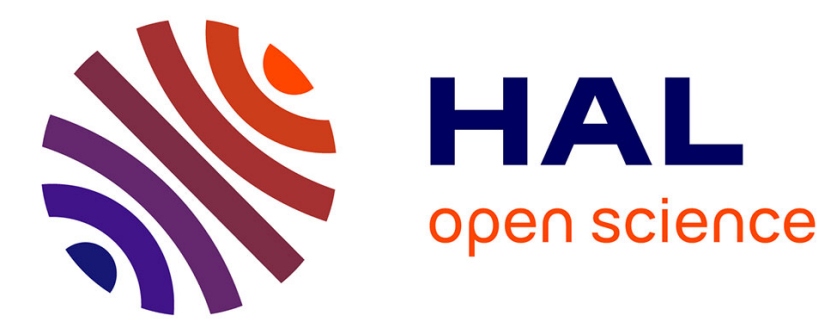

\title{
Dynamic hot forging of a steel connecting rod
}

A. Gilat, X. Wu, X. Zhang, R. Batra

\section{To cite this version:}

A. Gilat, X. Wu, X. Zhang, R. Batra. Dynamic hot forging of a steel connecting rod. Journal de Physique IV Proceedings, 1994, 04 (C8), pp.C8-533-C8-537. 10.1051/jp4:1994883 . jpa-00253444

\section{HAL Id: jpa-00253444 https://hal.science/jpa-00253444}

Submitted on 1 Jan 1994

HAL is a multi-disciplinary open access archive for the deposit and dissemination of scientific research documents, whether they are published or not. The documents may come from teaching and research institutions in France or abroad, or from public or private research centers.
L'archive ouverte pluridisciplinaire HAL, est destinée au dépôt et à la diffusion de documents scientifiques de niveau recherche, publiés ou non, émanant des établissements d'enseignement et de recherche français ou étrangers, des laboratoires publics ou privés. 


\title{
Dynamic hot forging of a steel connecting rod
}

\author{
A. Gilat, X. Wu, X.T. Zhang* and R.C. Batra* \\ Department of Engineering Mechanics, The Ohio State University, Columbus, OH 43210-1181, U.S.A. \\ * Department of Mechanical and Aerospace Engineering and Engineering Mechanics, University of \\ Missouri-Rolla, Rolla, MO 65401-0249, U.SA.
}

\begin{abstract}
An integrated study of dynamic hot forging of SAE 1151 steel connecting rod is presented. The study includes material characterization, constitutive modeling, and numerical simulation of the forging process. Results from torsion tests of the steel show that the material response is very sensitive to the deformation-rate and temperature at temperatures between 800 and $1000^{\circ} \mathrm{C}$. A viscoplastic constitutive relation that models the material response well under the aforestated test conditions is proposed and is implemented in an explicit three-dimensional finite element code. The numerical simulation provides the distribution of stresses, strains, the temperature, and the velocity at any instant during the forging process.
\end{abstract}

\section{INTRODUCTION}

Hot forging of metals involves large dynamic plastic deformations at temperatures close to their melting temperatures. Average strain-rate in hammer forging is typically in the range of $10-50 \mathrm{sec}^{-1}$. Locally, however, depending upon the product geometry, strain rates can be quite high. The response of steel depends greatly upon the temperature and the rate at which the deformation is taking place. Temperature and strain-rate effects are coupled since one influences other. Temperature affects the rate of deformation which is controlled by thermally activated mechanisms. At the same time, deformation at high rate can generate significant heating.

Frequently, the design of forging dies involves a trial and error approach that relies on empirical rules. Recently, numerical codes capable of modeling and simulating forging have been developed. A finite element code for this purpose should be capable of analyzing three-dimensional time dependent problems involving large plastic deformations. The quality of the computed results depends upon the constitutive relations used to model the material response of the forged material. The numerical modeling of forging processes has been reviewed by Gegel, Malas, Doraivelu, and Shende [1].

This paper describes an integrated study of hot forging of a connecting rod. It includes a detailed characterization of the material at the temperatures and strain-rates likely to occur during the forging process, development of viscoplastic constitutive relations that describe well the material response, and a finite element simulation of one stage of the forging process. 


\section{MATERIAL CHARACTERIZATION}

The SAE 1151 steel used for the forging was tested at various strain rates and temperatures ranging from $5 \times 10^{-4}$ to $1000 \mathrm{sec}^{-1}$ and 25 to $1000^{\circ} \mathrm{C}$. Torsion tests were conducted on short thin-walled tubes. Tests involving strain-rates up to $10 \mathrm{sec}^{-1}$ have been performed in a hydraulic Instron axial-torsion machine. A clam-shell quartz lamp furnace mounted around the specimen is used for heating the specimens. A closed loop controller keeps the temperature of the specimen, which is measured with a thermocouple that touches the inside surface of the specimen wall, within $0.2^{\circ} \mathrm{C}$ of the testing temperature. The specimen is connected to the heads of the machine through specially designed adapters made of MAR-M 246 superalloy. The torsion tests are performed by applying torque and keeping the axial force equal to zero. Tests at strain rates of about $1000 \mathrm{sec}^{-1}$ have been conducted with a torsional split Hopkinson (Kolsky) bar apparatus. A clam-shell quartz lamp furnace is used for heating in tests at temperatures up to $400^{\circ} \mathrm{C}$, and a specially designed heating technique is used for tests at higher temperatures. The latter heating method involves a specially built rapid heating device and a connection between the specimen and the bars that allows transmission of the torsional wave but minimizes heat conduction to the bars. Detailed description of the heating technique and a comparison with other methods are presented by Gilat and Wu [2].

Shear stress-strain curves obtained in tests conducted at temperatures of 800 and $1000^{\circ} \mathrm{C}$ are shown in Figs 1 and 2, respectively. Each figure shows results from tests at different strain rates. The results show that the material response is very sensitive to both temperature and strain rate.

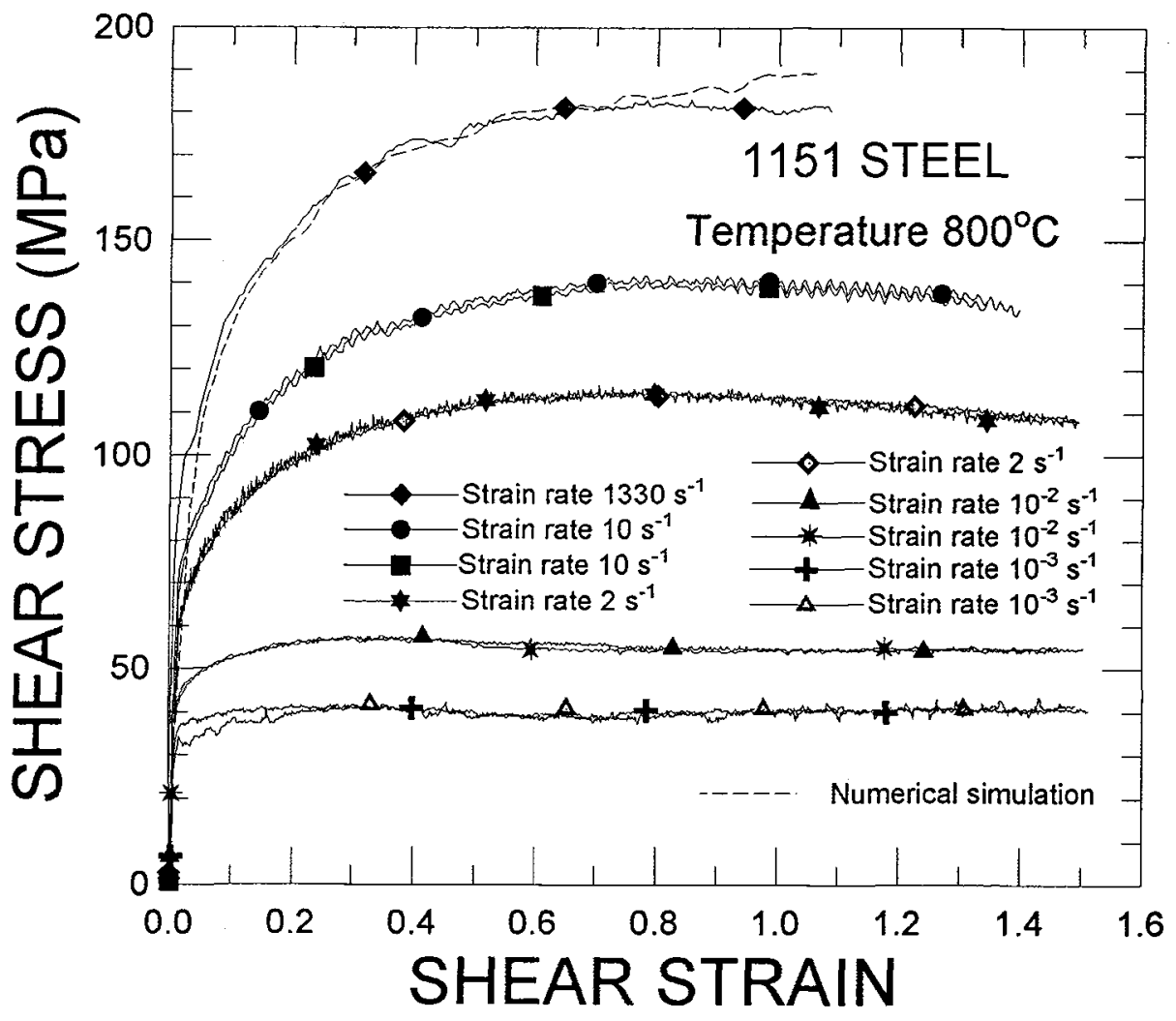

Fig. 1 Stress-strain curves for SAE 1151 steel at $800^{\circ} \mathrm{C}$. 


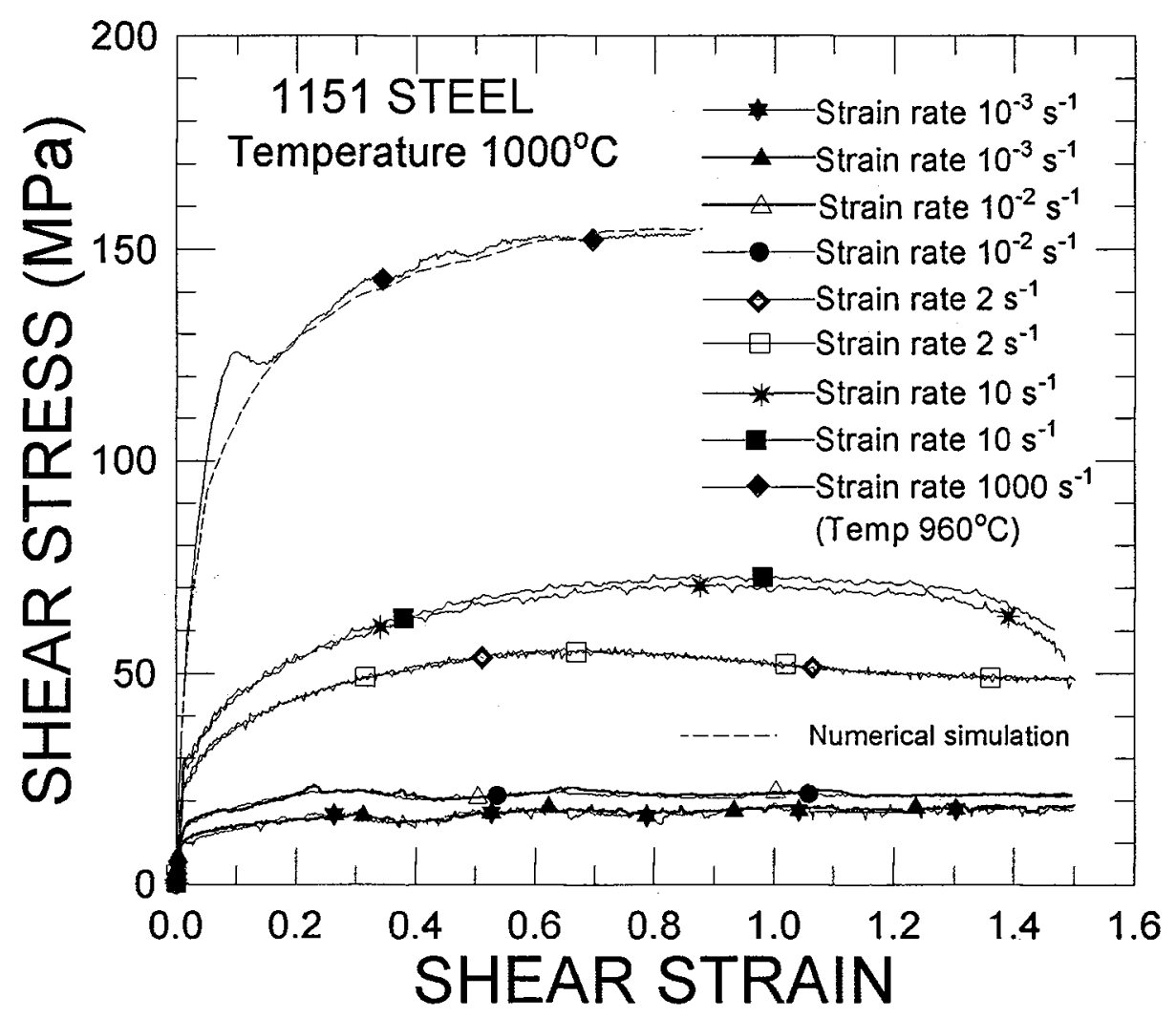

Fig. 2 Stress-strain curves for $\mathrm{SAE} 1151$ steel at $1000^{\circ} \mathrm{C}$ (the test at strain rate of $1000 \mathrm{sec}^{-1}$ was conducted at $960^{\circ} \mathrm{C}$ ).

\section{CONSTITUTIVE RELATIONS}

In developing the constitutive relation for the steel from the test data, it is assumed that the equivalent flow stress, $\sigma_{\mathrm{m}}$, of the material can be expressed as the product of three functions: one of temperature, another of strain, and a third one of strain-rate only. Explicit forms for these functions, determined from the test data, and verified by ensuring that the shear stress-strain curves obtained from the numerical simulation of the torsion tests matched well with the experimental one, are given below.

$\sigma_{\mathrm{m}}=\left(35.47+188.5 \exp \left(-\frac{1}{2}\left(\frac{1}{3.4194} \ln \frac{\gamma_{\mathrm{p}}}{2.152}\right)^{2}\right)\right)\left(1+0.096 \ln \left(\frac{\dot{\gamma}_{\mathrm{p}}}{\dot{\gamma}_{\mathrm{o}}}\right)\right)\left(1-\mathrm{T}^{1.23}\right) \quad \mathrm{MPa}$

Where $\dot{\gamma}_{0}=1 \sec ^{-1}, T=\left(\theta-\theta_{0}\right) /\left(\theta_{\mathrm{m}}-\theta_{\mathrm{o}}\right), \theta_{\mathrm{o}}$ equals the ambient temperature, $\theta$ the current temperature of material particle, $\theta_{m}$ the melting temperature of the material, and $\gamma_{p}$ and $\dot{\gamma}_{p}$ are the equivalent plastic strain and its rate, respectively. 


\section{NUMERICAL SIMULATION OF THE FORGING PROCESS}

The aforestated constitutive relation has been implemented in the explicit large scale threedimensional finite element code DYNA3D (Whirley and Hallquist, [3]). The high strain rate torsion tests were simulated with the code. As shown in Figs. 1 and 2 the computed curves match well with the experimental ones. During the simulation of the forging process the die is assumed to be rigid, the deformations of the workpiece are taken to be locally adiabatic, and the slideline algorithm is used to account for the smooth sliding of the workpiece material over the die surface. Figure 3 depicts the initial geometry of the workpiece and of the upper die; a die identical to the upper one is also at the lower end but is not shown in the figure. Because of the symmetry of the problem about the vertical and horizontal centroidal planes, only a quarter of the problem domain is studied, but some of the results presented below are for the entire region.

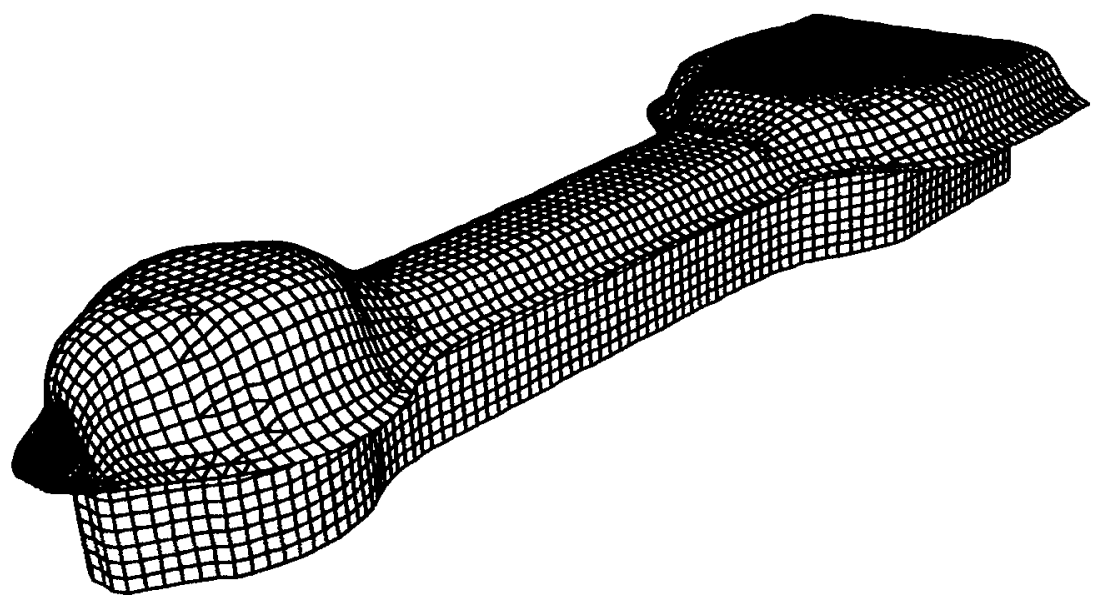

Fig. 3 Initial geometry of the workpiece and the die shape

Figure 4 evinces the deformed shapes of the workpiece at 500,1000, and $2300 \mu \mathrm{sec}$ after it is suddenly loaded. It is clear that the code can simulate the flow of the material into sharp corners. Figure 5 shows contours of the equivalent plastic strain at the final time of $2600 \mu \mathrm{sec}$ when the bottom surface of the upper die reaches the midsurface of the workpiece signifying completion of the forging process. The equivalent plastic strain assume maximum values at points where the flow of the material changes noticeably.

\section{ACKNOWLEDGMENTS}

This research was supported by the US National Science Foundation, Grants No. MSS-9114258 and MSS-9121279 to the Ohio State University and the University of Missouri-Rolla, respectively. Some of the computations were carried out on the Ohio State University Cray Supercomputer center.

\section{REFERENCES}

[1] Gegel H.L., Malas J.C., Doraivelu S.M. and Shende V.A., Metal Handbook, 9th ed. Am. Soc. Metals 14 (1988) pp. 406-442. 
[2] Gilat, A. and Wu, X, "Elevated Temperature Testing with the Torsional Split Hopkinson Bar," Experimental Mechanics 34, (1994).

[3] Whirley, R.G. and Hallquist, J.O., DYNA3D User's Manual "A Nonlinear, Explicit, Three-Dimensional Finite Element Code for Solid and Structural Mechanics," UCRL-MA-107254, University of California, Lawrence Livermore National Laboratory, (1991).

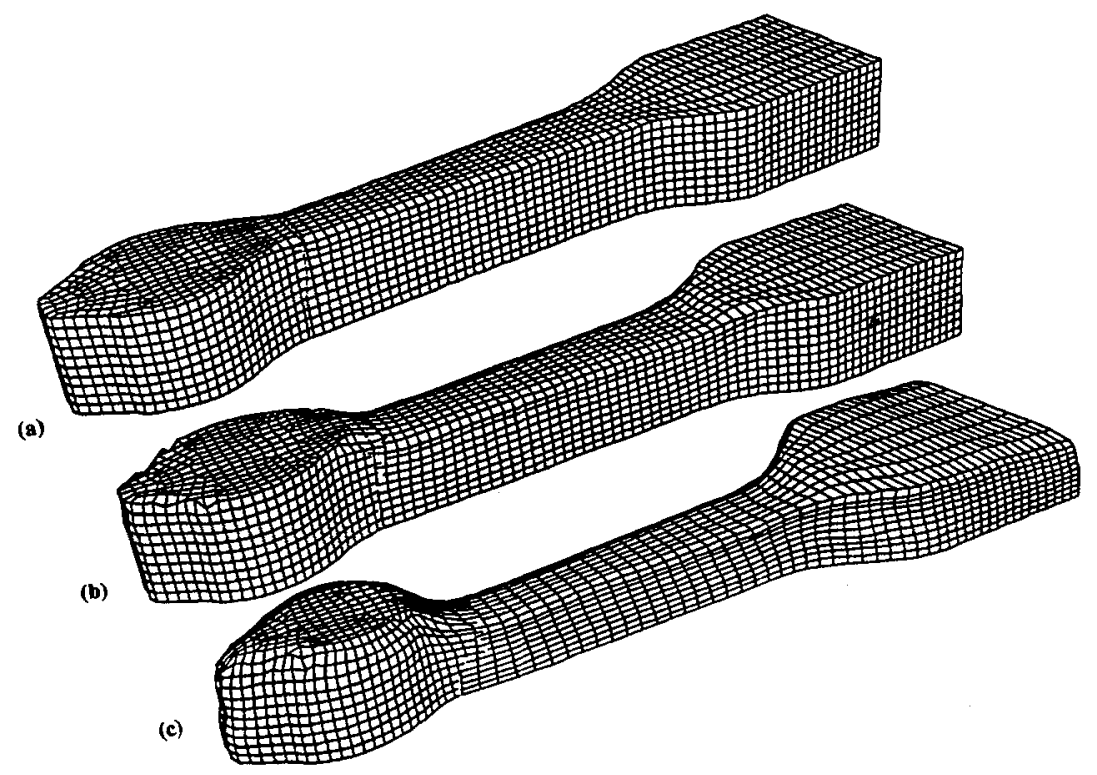

Fig. 4 Deformed shapes of the workpiece at (a) $t=500 \mu \mathrm{sec}$, (b) $t=1000 \mu \mathrm{sec}$, and (c) $t=2300 \mu \mathrm{sec}$.

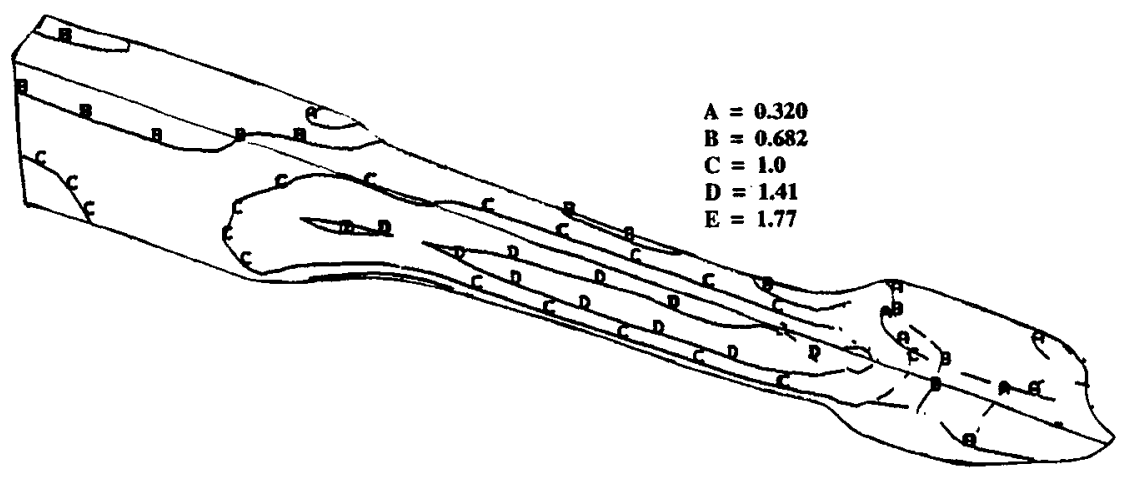

Fig. 5 Contours of the equivalent plastic strain in the deformed workpiece at $t=2600 \mu \mathrm{sec}$. 